\title{
Interview
}

\section{Crisis and Critique: On Preparedness, Authoritarianism and the Regulatory State}

\author{
Interview with Carlo Caduff \\ Department of Global Health and Social Medicine, King's College London, \\ United Kingdom \\ carlo.caduff@kcl.ac.uk
}

\begin{abstract}
The Covid-19 pandemic has been overwhelming in many ways, but what are the structural conditions that can explain the dramatic impact of the global pandemic? How can we shift the horizon of the possible and contribute to another politics of life, one that is based on strong institutions and a vision of social justice? This article examines the role of preparedness, authoritarianism and the regulatory state. It suggests that it is important to move beyond the binary of epidemic and endemic disease and rethink the kinds of crisis publics, forms of political action and medical-historical consciousness that this distinction with its emphasis on dramatic disjunctures enables.
\end{abstract}

\section{Keywords}

pandemics - preparedness - authoritarianism - capitalism - inequality - social justice 
- PARISS Editors: You published your piece 'What went wrong: Corona and the world after the full stop' in July 2020 (Caduff 2020). Here, you discussed the difficulty of forming a critique of government responses to Covid-19 because of the impossibility to escape from the impetus to be 'responsible.' Where and how do you see the space for critique now? Are there necessarily limits?

It has been difficult to escape the sense of dread amplified by a constant stream of disturbing news. Just as the virus is spreading across the world and the number of sick and dead people is rising, there is a lot of information that is circulating through all kinds of public and private channels. Processing that information and finding one's place and one's voice in the heterogeneous public spheres of the pandemic is not an easy task, not least because of the sheer amount of information and the confusions and contradictions it produces.

At the start of the pandemic, people were surprised and shocked - surprised because of the rapid spread of the virus and shocked because of the massive response to it. The lockdown - an unprecedented social experiment never implemented for any disease at such a scale - led to a growing sense of isolation, depression, attrition and exhaustion. Public speech took the form of instructions, accusations and moralizations.

As I mentioned in my article, lockdowns entail a distinct class politics and create differential exposures to the disease. In India, serological studies showed that the first wave affected predominantly the working poor. Living in crowded conditions, the strict ban on any kind of movement exposed them to the local circulation of the virus. Meanwhile, the middle and upper classes were protected by the lockdown in their secluded worlds. The second wave started in February 2021. The impact of the disease became much more visible because it now predominately affected the middle and upper classes, educated people who can access social media and make themselves visible in public. In the absence of a national lockdown, rapidly rising infections and an overburdened healthcare system, public speech took the form of desperate cries for help.

This makes comparison between waves difficult. India's middle classes can make their plight visible today, a capacity distributed unequally across class due to differential access to media, technology and power. The promise of post-liberalization India was that it would insulate the middle classes from the plight of the poor who can't access healthcare on a daily basis. Today's outrage at the lack of preparedness will hopefully lead to a more inclusive politics of health rather than more insulation. 
The aim of my piece, published in 2020, was to take a step back, look beyond the immediacy of the event and the urgency of the response, and open up a space for critical reflection. Critique, in the sense of blame and accusation, is widespread. But these incisions only intensify the vicious cycle of crisis and critique that historian of modernity Reinhart Koselleck identified six decades ago (Koselleck 1959).

My aim was to offer a different form of critical reflection and avoid the intensification of crisis discourse. I found it curious that people thought this crisis could be solved by having more crisis discourse. For a position beyond crisis, it is essential to stay away from everything that helps maintain a pervasive feeling of fear and panic because it blinds people with a false sense of clarity and certainty (see Roitman 2013). The challenge was to convey the idea that such a position beyond crisis could itself be a form of taking responsibility in a situation of deep uncertainty. This seemed crucial to me because crisis is incredibly amendable to instrumentalization.

The aim of the critical reflection was to first, emphasize structural conditions; second, explore consequences; and third, shift the horizon of the possible.

Over the past months, scholars have published acute analyses of the pandemic and the response to it, highlighting the structural conditions that led us to the dreadful place where we are now. One piece that I found particularly insightful is Lee Jones' and Shahar Hameiri's account of the British pandemic response, published in the Review of International Political Economy (Jones \& Hameiri 2021). This piece is relevant beyond Britain, because it shows how the massive failures that we have witnessed at both national and international levels can only be understood in relation to the emergence of the "regulatory state" over the past four decades. Similar to my own piece, Jones and Hameiri emphasize that the pandemic was neither unprecedented - infectious diseases kill millions of people year after year, HIV/AIDS alone killed over 33 million people - nor unexpected - over the past three decades public health professionals and government officials have been preparing intensively for a catastrophic pandemic (Caduff 2015). The failure in the pandemic response happened despite decades of pandemic planning and preparing.

Jones and Hameiri argue that over the past three decades, 'government' was largely "replaced by 'governance', whereby resources, authority and responsibility are dispersed to diverse public and private actors, while central state managers retreat to a 'regulatory' role, using 'negative coordination' to 'steer' these actors in broadly favoured directions." As a result of this process, the state has neither the capacities nor the authority to actually control the spread of an infectious disease such as Covid-19. Instead, it relies on attempts to regulate 
other actors and outsource critical capacities such as testing and contact tracing. Unfortunately, this is also true for international organizations such as the World Health Organization. Its main function is to advise, regulate and standardize. Beyond that it has very little actual capacities.

Yet a pandemic of this nature cannot be contained by regulation alone. This leads me to four broader conclusions:

1.) What has been called pandemic preparedness in the past three decades is an exemplary form of regulatory governance. Pandemic preparedness took the form of plans for a catastrophic outbreak of infectious disease. These plans created an illusion of coherence and control in a world marked by systematic fragmentation and diffusion of resources and responsibilities. The aim of international preparedness plans was to consider possible scenarios, outline general principles and inform the development of national plans while national plans aimed to inform the development of regional plans which in turn were supposed to inform local plans. In this hierarchical mode of planning, agencies instructed other agencies and officials advised other officials while very little actual capacities in logistics, infrastructure and intelligence were created in the process.

2.) Preparedness plans predicted breakdowns. But rather than devoting new resources to prevent breakdowns, they mainly focused on strategies of deploying existing resources to mitigate the impact of expectable and presumably unavoidable breakdowns. I have described this in The Pandemic Perhaps as a shift from excess capacity to surge capacity (Caduff 2015).

3.) It is not the spread of the virus that has made lockdowns necessary, it is regulatory governance and its inherent limitations that made lockdown the only available option in many places.

4.) The lockdown is not only symptom of the pathologies of regulatory governance, it is also the limit point of regulation itself. The ban of everything, what I termed the "full stop," is the most extreme form of a regulatory intervention. This means that the lockdown is indeed emblematic of the more general political situation in which we find ourselves today.

- Something that stood out in this paper was your assertion that "[I]t is important to understand that the strategic combination of confusion, contradiction, and the play of extreme opposites is foundational for authoritarian rule." And your insistence that "another politics of life is possible". In the UK, we are currently witnessing a permanent assault on freedom of assembly from a government which was already known for its authoritarian tendencies. What does another politics of life look like now? Does the situation look more urgent? 
It does look more urgent, in my view, precisely because there is still a lot of work necessary for us to better understand the recent rise of authoritarianism. The important point is that authoritarians are not necessarily coherent in terms of their political actions and orientations. Consider this example: In India, Prime Minister Narendra Modi imposed an extreme lockdown for several months during the first wave of the pandemic to "save each and every life," as he emphasized. Now, a year later, in April 2021, with a second wave under way and higher numbers of infected people, there is no national strategy in place. Instead, government officials, including Modi himself, are busy attending political rallies in West Bengal, Assam and Kerala where local elections are due, drawing huge crowds of people without any form of physical distancing and largely without wearing masks.

Similar to Johnson, the great refuser of the lockdown who eventually became its staunch defender, Modi shifted into the opposite and now looks like another incarnation of Bolsonaro who thinks it is best to let the pandemic take its course. Authoritarian rulers are always what they are as well as their opposite. They can shift from one extreme to the other. One might say they embody their own critique, drawing energy from the spectacle of crisis and critique that propels them forward.

I am not sure how useful notions such as "soft authoritarianism" or "electoral authoritarianism" are in this context. They seem to reflect the confusions and concerns of scholars who are troubled by the realization that authoritarianism and democracy are not opposed to each other. These notions may thus say more about liberalism as a political philosophy and its implicit theories of history and modernity rather than what is actually happening today in many places across the global North and the global South.

My friend and colleague Maria José de Abreu recently noted how our very understanding of exception - reflected in notions such as the "state of exception" or the idea that Trump somehow represents a deviation from ordinary politics tends to reproduce the "temporal logic of a narrative of exception" (Abreu 2021). She suggests that the analytic of exceptionalism fundamentally misses its target. Politicians such as Trump create an aura of sovereign exceptionalism, but actually rule by chaos, disruption and distraction. In accusing Trump of authoritarian exceptionalism, scholars are unable to understand how Trump relies much more on "incisions" rather than actual "decisions." With an outdated political language of exceptionalism, scholars reinforce Trump's aura of sovereignty while at the same time obscuring the insidious modus operandi of this form of governance by disruption. Such a type of critique ends up creating the conditions for its own crisis because it contributes to the reproduction of what it opposes.

Scholars such as Vladimir Safatle place the pandemic response in the context of "authoritarian neoliberalism," emphasizing the inability of these forms 
of governance "to produce macro-structures of social protection and redistribution in a scenario of worsening inequalities and concentration (Safatle 2020)." Authoritarian neoliberalism seems a more accurate concept compared to "soft" or "electoral" authoritarianism because it highlights the ideological foundation of this form of governance. This brings me back to the regulatory state, which is as hollow at its core as the authoritarian ruler. Therein lies their affinity.

It is well known and has been well documented how state capacities have been deliberately undermined over the past decades by austerity policies. Yet each time the state fails it is presented as another seemingly self-evident proof of how the state is unable to manage social problems. This is the self-fulfilling prophecy at the heart of neoliberalism: state failure is not a problem for the state, on the contrary, failure is a feature of the system, it is the condition of possibility for the continuing hollowing-out of the state and the systematic outsourcing of evermore state functions. This outsourcing makes enormous public funds available to private actors which are then supposed to address social issues in health, education and housing.

Britain's approach to testing and contact tracing is a case in point. In March 2020 , the testing and contact tracing effort was abandoned because the state simply didn't have the required infrastructure. After massive public pressure, the government improvised and announced a new system relying predominantly on out-scouring and sub-contracting to private companies. The new system involved the management consulting company McKinsey and the audit firm Deloitte in addition to thousands of private-sector consultants. It took months to set up, cost billions of pounds and has never been performing as it was supposed to perform. Such state failure is both a result of regulatory policy as well as its condition of possibility.

Recently Prime Minister Boris Johnson suggested that the reason for the UK's vaccine success was because of "capitalism," because of "greed." The irony, of course, is that in the case of the AstraZeneca vaccine (and, in fact, in the case of most other vaccines for Covid-19) it was actually massive public funding that enabled the development of the vaccine by researchers from the University of Oxford. When the management of the university promised to donate the rights to the vaccine to any drug-maker willing to manufacture it, global health philanthropist Bill Gates stepped in and urged the university to reverse its course and negotiate a deal with a major player such as AstraZeneca. The agreement that was eventually signed gave the British-Swedish pharmaceutical company exclusive rights to the vaccine.

After providing public funds to develop and manufacture vaccines, the public sector is now purchasing these vaccines from private companies, which had to bear no risks and no expenditures of their own. Clearly, global health 
capitalists such as Bill Gates know how to use a crisis and protect pharmaceutical profits and the structure of intellectual property rights on which they are based. This happens hardly for the benefit of the public.

The irony here is that the state subsidizes research and development with public money only to go on and create an oligopolistic market for vaccines dominated by a small number of pharmaceutical companies on which the state then depends.

In April this year, the Serum Institute of India, a private company manufacturing the Oxford University / AstraZeneca vaccine asked the Indian government to remove the cap on the price of the vaccine. In an interview published at the outset of India's second wave, the company's CEO noted: "I would not say we are not making any profits, but we have sacrificed what we call super profits." The start of the second wave with a rapidly rising number of dead people piling up on cremation grounds seemed to be the right time to realize super profits. The Indian government agreed to provide the Serum Institute a 610 million dollar grant to increase manufacturing capacity. The company in turn revised the original price of 150 rupees per dose and made it three times more expensive for government procurement and four times more expensive for private providers. The main aim of increasing the price was to make more profit.

Today, systematic effort goes into the ideological project of making the state seem weak and the market seem strong. Paradoxically, representatives of the state quietly undermine expectations and accounts of public authority and state capacity. The reason is simple: The state thrives on state failure. When there is success, it attributes it to the role of private actors. And when private actors fail, it takes the failure as an opportunity to affirm its own role as regulator. This makes it very difficult for scholars to articulate a critique of the state, because it feeds into the spectacle of crisis and critique that is so fundamental for our current political moment and its inability to imagine other futures.

Building strong institutions and creating actual capacities that are inspired by a vision of social justice and that are based on an ethics and politics of mutual support is more urgent today than ever. There is a need to strengthen fragile public infrastructures to tackle enduring forms of structural economic precarity, reverse the global trend of growing inequality and expand access to public goods such as healthcare, education and housing both in the global North as well as the global South. One can only hope that the pandemic will spur social movements that bring people together and enable collective action to change structural conditions.

- The logic of restrictions, at least in the UK has changed from the actuarial imaginary of case prevalence and overwhelming the NHS, to imaginaries of 
variants which could potentially evade vaccine efficacy. What is your take on this constantly shifting politics of 'perhaps'?

This is a great question and a really important one. The concern with variants emerged relatively late in the course of the pandemic. There was hardly any public discussion of variants during the first wave. The imaginary of variants and the concern with mutations took shape in December 2020, when a new variant was made responsible for the second wave in the UK. The UK government used the variant to justify a dramatic reversal in lockdown policy, which happened just before the culturally and politically sensitive time of Christmas. Here, as in so many other contexts, we can see how science and politics become inextricably entangled. But the challenge is not to separate science from politics - there is no position of innocence that would be available to us. Instead, we should follow a long tradition of feminist and science \& technology scholarship and study the constitution of distinct entanglements of science and politics and ask how another science and another politics might be possible.

It will probably take some time until we better understand the role of viral mutation in this pandemic. But a few more general points may be useful here for our orientation:

1.) Mutations are very common, and different viruses have different mutation rates. The influenza virus, for example, is known for its high mutation frequency. Coronaviruses, by contrast, have generally a much lower mutation frequency.

2.) It is often very difficult to correlate microbiological investigations of viruses with epidemiological observations of epidemics, mainly because mutation is only one factor that may account for a changing epidemiological pattern. Whatever we observe will always be multifactorial and contextual - and so one might want to highlight the complex nature of infectious diseases especially when they are spreading at such a scale. The tendency today is to either explain everything by reference to the nature of the virus, or by reference to the behavior of people, or by reference to the impact of lockdowns. Typically, these explanations are concomitantly used to criticize actions while deflecting criticism from oneself.

3.) Whatever happens is never reducible to a single factor and should be studied with an understanding of how local biologies intersect with local socialities. Such efforts at understanding are unfortunately rare, mainly because the politics of it are unclear and less predictable. Also, who wants a complex answer to a simple question? There is a need for instant 
judgement and there is a desire for clear instructions. The truth is that it might well take us years if not decades to really understand what has been happening.

4.) There is so much that is not known in terms of why and how infectious diseases are spreading in human and non-human populations. For example, scientists are still not quite sure why influenza is following a seasonal pattern. This seems like a basic scientific question, but what we have until now in terms of understanding influenza waves are primarily hypotheses. There is no coherent answer and there is no agreement among scientists. To assume that we know more about the spread of SARS-CoV-2, which is a pathogenic agent never even close to have been studied for as long as influenza, seems not very convincing to me.

Whether variants will escape vaccine-induced immunity is difficult to say today. We will have to wait for another few months in order to better understand what the actual efficacy of the different vaccines is in a real-world context. Of course, for pharmaceutical companies it will be much more profitable if new variants appear which require new vaccines and/or if the artificially induced immunity in humans wanes off after some time. In fact, pharmaceutical companies have already announced that more than two shots will be necessary and that they will determine the future price of the Covid-19 vaccines on their own once the immediate pandemic is over - clearly they are of the opinion, or want us to believe, that continued vaccination will be necessary.

Here, again, in our predicament of the perhaps, there is science, politics and a lot of money involved. The tendency in today's world is to read crisis into every new variant. We might want to take a step back and ask the question about the stakes that are involved in such a reading.

- Let me ask you a final question: When and how will this pandemic end?

This is a great question, rightly reserved for the end. There are many reasons that make the end of the pandemic so compelling as an idea. We all wish this nightmare to be over as soon as possible. To save lives, but also to abandon our current isolation and regain and rebuild our existence as social beings in relation. But it is not as simple as that. We need to look beyond our own desire for an end here. The past decade has seen an immense concentration of wealth in the hands of a few individuals and companies, and this pandemic and the response to it have only accelerated this deeply troubling trend. So clearly not everyone is looking forward to the end of the pandemic in the same way; it really depends on where you stand in the global distribution of health, wealth and power. The 
key question is how understandings of the end might enable/disable political projects and collective action that promote equity and social justice.

The virus is unlikely to disappear. Even vaccination will not eradicate it. It is most likely to become an endemic virus, like the other four coronaviruses that have been circulating in humans for decades. This means that the waves might continue, but hopefully on a much lower scale and with less morbidity and mortality. The continuing circulation of the virus will make identification of an end really difficult if not impossible.

Historian of medicine Charles Rosenberg suggested that epidemics are characterized by an episodic quality: They are events with clear beginnings and clear endings. In his view, "epidemics start at a moment in time, proceed on a stage limited in space and duration, follow a plot line of increasing and revelatory tension, move to a crisis of individual and collective character, then drift toward closure" (Rosenberg 1989). However, this narrative form is really limiting as an analytic. Kavita Sivaramakrishnan, Dora Vargha and Jeremy Greene urged scholars to move away from such interpretations of epidemics that present them as finite and episodic. As Sivaramakrishnan underscores, these interpretations neglect "the persistence of social vulnerabilities and accumulated risks associated with epidemics and the links to events and susceptibilities that occurred before and after that make up an epidemic's life-course" (Sivaramakrishnan 2021) This is a really important point because it emphasizes how a focus on a single virus and a single event can obscure the broader ecology of health and disease within which infections occur. Let's not forget that alongside Covid-19, there are continuing, overlapping outbreaks of malaria, tuberculosis, HIV/AIDS, dengue, influenza, and so forth.

Sivaramakrishnan raises a number of crucial questions in her piece that can provide our thinking with a new orientation: "What kinds of epidemic history writing needs to emerge in an age that is now removed from the triumphal politics and claims of modernity and globalization and is associated with the ambivalence and politics of recurring risks and returning pandemics? What are the specific political possibilities that epidemic crises open up and limit: when middle class, liberal voices across societies assume registers of outrage and empathy vis à vis the suffering experienced by marginalized communities but are fundamentally unwilling to suggest structural sacrifices and welfare reform, and often satisfied by expressing hashtag solidarities?"

Epidemics have often only ended "through widespread acceptance of a newly endemic state," as Jeremy Greene and Dora Vargha note (Greene and Vargha 2020). It seems time, then, to move beyond the binary of epidemic and endemic disease and rethink the kinds of crisis publics, forms of political action 
and medical-historical consciousness that this distinction with its emphasis on dramatic disjunctures enables. Instead we should investigate the less visible interactions of the acute and the chronic, including examining who and what determines whether a condition counts as epidemic or endemic in the first place. Rather than declaring the end of the pandemic, our task is to reveal what understandings of disease such a declaration implicitly entails and what it might obscure and sideline. These are only some indications that hopefully suggest what might be at stake in the idea, the hope and the promise of an end.

\section{References}

Carlo Caduff: What Went Wrong: Corona and the World after the Full Stop, in: Medical Anthropology Quarterly, Dec 2020; 34(4):467-487.

Carlo Caduff: The Pandemic Perhaps, University of California Press 2015.

Maria José de Abreu: Rabble-Rousers Without Exception, in: Cultural Anthropology Forum on American Fascism 2021.

Jeremy Greene and Dora Vargha: How Epidemics End, in: Boston Review 2020.

Lee Jones and Shahar Hameiri: Covid-19 and the Failure of the Neoliberal Regulatory State, in: Review of International Political Economy, 2021.

Reinhart Koselleck: Crisis and Critique, MIT Press 1988.

Janet Roitman: Anti-Crisis, Duke University Press 2013.

Charles Rosenberg: What is an Epidemic? AIDs in Historical Perspective, in: Daedalus 1989 .

Vladimir Safatle: Beyond the Necropolitics Principle. Suicidal State and Authoritarian Neoliberalism, in: Crisis and Critique 2020.

Kavita Sivaramakrishnan: Looking Sideways. Locating Epidemics and Erasures in South Asia, in: Bulletin of the History of Medicine, 2021. 